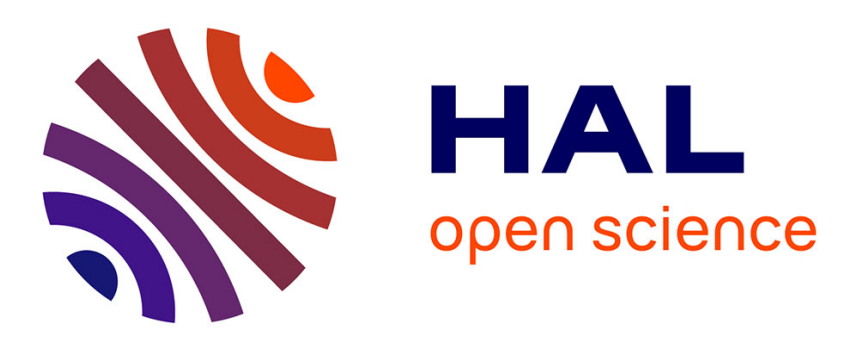

\title{
Micromechanical Modelling of the Damage and Toughness Behaviour of Nodular Cast Iron Materials
}

W. Brocks, S. Hao, D. Steglich

\section{To cite this version:}

W. Brocks, S. Hao, D. Steglich. Micromechanical Modelling of the Damage and Toughness Behaviour of Nodular Cast Iron Materials. Journal de Physique IV Proceedings, 1996, 06 (C6), pp.C6-43-C6-52. 10.1051/jp4:1996605 . jpa-00254433

\section{HAL Id: jpa-00254433 https://hal.science/jpa-00254433}

Submitted on 1 Jan 1996

HAL is a multi-disciplinary open access archive for the deposit and dissemination of scientific research documents, whether they are published or not. The documents may come from teaching and research institutions in France or abroad, or from public or private research centers.
L'archive ouverte pluridisciplinaire HAL, est destinée au dépôt et à la diffusion de documents scientifiques de niveau recherche, publiés ou non, émanant des établissements d'enseignement et de recherche français ou étrangers, des laboratoires publics ou privés. 


\title{
Micromechanical Modelling of the Damage and Toughness Behaviour of Nodular Cast Iron Materials
}

\author{
W. Brocks, S. Hao and D. Steglich \\ Department WMG, GKSS-Forschungszentrum Geesthacht, Postfach 1160, 21494 Geesthacht, Germany
}

\begin{abstract}
The strength and toughness of nodular cast iron materials is described by a micromechanically based damage model for porous plastic materials. Two ferritic nodular cast iron materials of the type GGG-40 with different graphite morphology are investigated. Quantitative metallurgy and cell model calculations are used to determine the characteristic parameters of the Gurson-Tvergaard-Needleman-model (GTN-model). The stress strain behaviour of the matrix is obtained from tensile tests on a pure ferritic material. The influence of stress triaxiality and void shape on the critical void volume fraction is studied. Tensile tests with smooth and notched specimens are simulated to verify the load-deformation behaviour. The effect of the graphite morphology on fracture toughness is studied by tests and simulations of SE(B)-specimens.. Fracture resistance curves can be well predicted. A correlation between element size and particle distance is found.
\end{abstract}

\section{INTRODUCTION}

The increasing application of nodular cast iron in structures and components requires a detailed characterization of this material to predict its toughness and damage behaviour at static loading in dependence on the graphite morphology. The application of micromechanical damage models extended the methods of safety assessment avoiding the problems of geometry dependent parameters as in conventional fracture mechanics.

The general advantage of micromechanical damage models, is that, in principle, the parameters are only material and not geometry dependent. The identification and determination of the required micromechanical parameters is still a rather new approach and no generally accepted recommendations exist. One way to determine these parameters is the use of a hybrid methodology of combined testing and numerical simulation [1]. Another way is based on the idea, that the physical process of damage in ductile media can be described by the structural behaviour of relatively simple unit cells [2]. Seperating the effects of intervoid matrix yield behaviour and void size and shape is one main advantage of this method.

Nodular cast iron has a nearly ideal microstructure for microscopical investigations. The diameter of the spherical or ellipsoidal graphite inclusions is about $10 \mu \mathrm{m}$ to $100 \mu \mathrm{m}$. Thus, material damage can be determined by optical microscopy and the results can be compared with numerical predictions based on micromechanical damage models. Additionally, nodular cast iron has a rather high void volume fraction of graphite, so that the inclusions cause a significant drop of the load carrying capacity. By testing both, a specially designed matrix alloy without graphite inclusions and the nodular cast iron material, it is possible to study the effects of matrix yield behaviour and graphite morphology separately. 


\section{TEST MATERIALS}

Two different materials with different graphite morphology were investigated which had been taken from transport containers for waste nuclear fuel rods. First, a material with nearly spherical inclusions (GGG$40 / 1 \mathrm{AZ}$ ) was tested to investigate the effect of particle size on the evolution of damage. A second material with more ellipsoidal inclusions (GGG-40/3AZ) was studied with respect to the effects of the particle shape. Figure 1 shows the two different materials. GGG-40/1 AZ has a void volume fraction of graphite of $11.4 \%$, which is assumed to be the initial value of damage, $f_{0}$. The shape of the inclusions was described in terms of its shape factor $S_{\mathrm{F}}$, defined as the ratio of cross section and circumference of the particle, $S_{\mathrm{F}}=4 \pi A / C^{2}$, which has the value of $S_{F}=0.85$ for GGG-40/1AZ. The second material, GGG-40/3AZ, has a void volume fraction of $12 \%$ and a shape factor of $S_{\mathrm{F}}=0.7$. Due to the larger diameter of the inclusions the nearest neighbour distance is the double compared to GGG-40/1 AZ, which can be seen in Figure 1 .
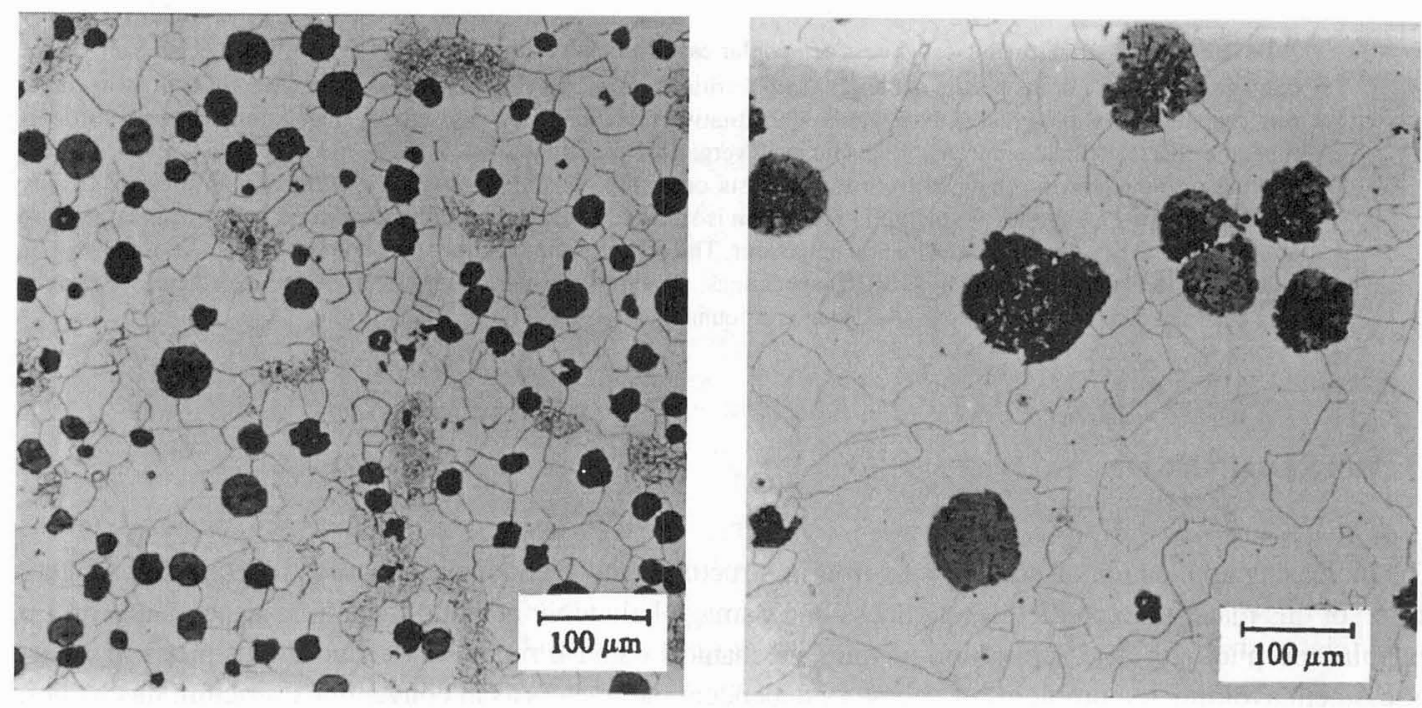

Figure 1: Microstructure of GGG-40/1AZ (left) and GGG-40/3AZ (right)

A separate description of the mechanical behaviour of the matrix material and the graphite inclusions is necessary for the micromechanical modelling. The manufacturing of a ferritic bulk material which has the same mechanical properties as the matrix material in cast iron was performed. Its yield curve was verified by comparing experimental results with numerical simulations using the von Mises yield condition. The experimental part of the present study was done at the TU Bergakademie Freiberg, FRG.

\section{CONSTITUTIVE EQUATIONS}

The constitutive equations which are used to describe ductile fracture processes are based on relatively simple models of microvoid nucleation, growth and coalescence [3, 4]. The application of these simple micromechanical models is justified by a statistical averaging effect over a large number of "unit cells" on the macroscopic scale, see Figure 2. 

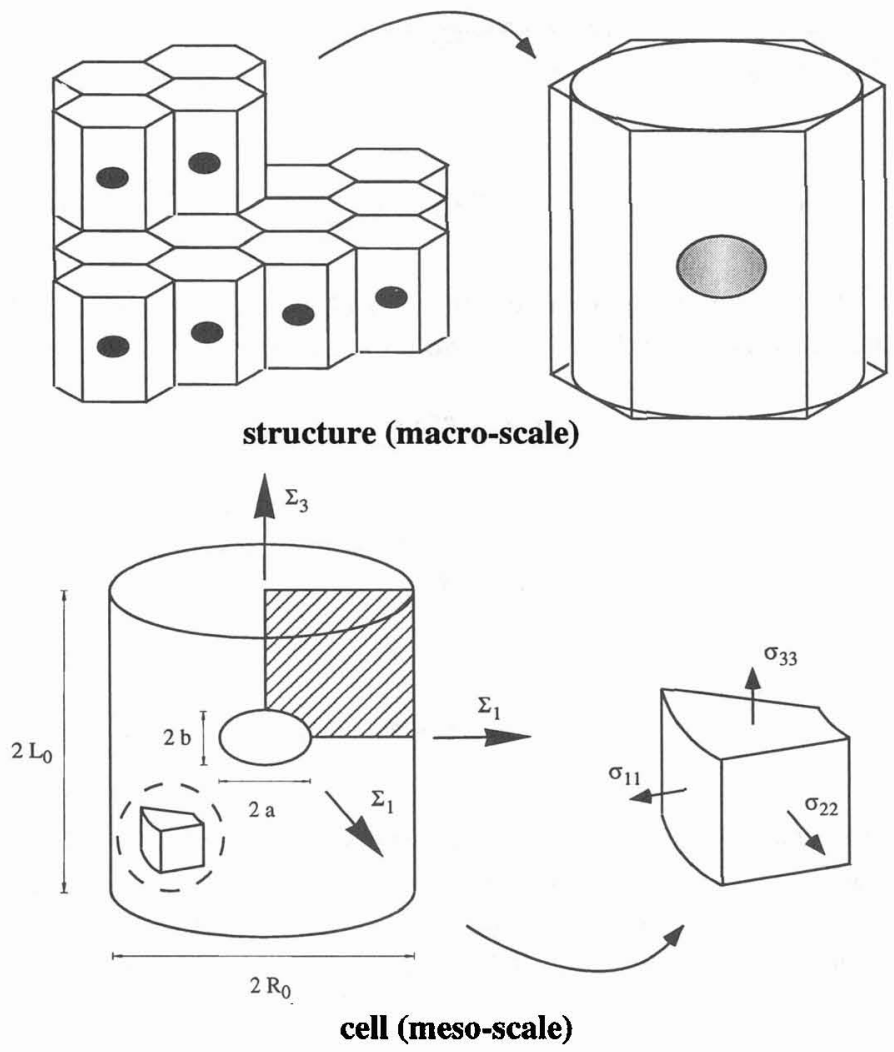

Figure 2: Unit cell representing a part of a structure

The constitutive equations of porous plastic solids base on a model which Rice and Tracey [3] developed for the early stages of void growth in terms of a single spherical cavity in an infinite plastic solid. The basic relationship that the growth rate of the cavity depends exponentially on the triaxiality of the stress state was used by Gurson [4] to describe the plastic yielding of a porous continuum. Plastic flow does not only depend on the accumulated plastic strain, $\varepsilon^{p}$, but, according to this model, on a second internal variable, the void volume fraction, $f$, which is defined as the ratio of the total volume of all cavities to the volume of the body and is introduced as an internal variable to characterize the damage. Its evolution equation consists in general of two terms due to nucleation and growth

$$
\dot{f}=\dot{f}_{\text {growth }}+\dot{f}_{\text {nucl }} \text { with } f\left(t_{0}\right)=f_{0} .
$$

$f_{0}$ is the initial void volume fraction. It was assumed that $f_{0}$ is equal to the initial volume of the graphite inclusions and that the voids will grow around these inclusions, so no nucleation contribution has to be considered. After a microvoid has nucleated in a plastically deforming matrix it undergoes a volumetric growth and a shape change. Only the volumetric change, however, can be described by the scalar quantity $f$. The void growth rate is proportional to the plastic volume dilatation rate

$$
\dot{f}_{\text {growth }}=(1-f) \operatorname{trD}^{p},
$$

where $\mathbf{D}^{p}$ is the plastic part of the strain rate tensor. The original assuption that the microvoids do not interact is not justified for modelling the final stage of void growth when coalescence of voids by localized 
internal necking of the intervoid matrix occurs. Tvergaard [5], Tvergaard and Needleman [6] therefore introduced an empirical modification of Gurson's yield function with three additional parameters, $q_{1}, q_{2}$ and $q_{3}$

$$
\Phi(\mathbf{S}, f, \sigma)=\frac{3 \mathbf{S}^{\prime} \cdot \mathbf{S}^{\prime}}{2 \sigma^{2}}+2 q_{1} f^{*} \cosh \left(q_{2} \frac{S p \mathbf{S}}{2 \sigma}\right)-\left(1+q_{3} f^{* 2}\right)=0
$$

$\mathbf{S}$ and $\mathbf{S}^{\prime}$ are the (mesoscopic) Cauchy stress tensor and its deviator, respectively, $\sigma\left(\varepsilon^{p}\right)$ is the actual flow stress of the matrix material which follows the evolution equation

$$
\dot{\sigma}=H\left(\varepsilon^{p}\right) \dot{\varepsilon}^{p}
$$

In many applications the parameters $q_{2}$ and $q_{3}$ are set to $q_{2}=1, q_{3}=q_{1}{ }^{2}$. The remaining parameter $q_{1}$ holds for an earlier loss of the stress carrying capacity of the materials as in Gurson's original yield function. Additionally, a damage variable, $f^{*}$, is introduced by

$$
f^{*}=\left\{\begin{array}{cl}
f & \text { for } \quad f \leq f_{c} \\
f_{c}+K\left(f-f_{c}\right) & \text { for } \quad f>f_{c} \quad \text { with } K=\frac{f_{u}^{*}-f_{c}}{f_{f}-f_{c}}
\end{array}\right.
$$

accounting for the coalescence of voids which occurs after a critical void volume fraction, $f_{c}$, is reached. This modification will be referenced as GTN-model in the following. The crack appears if the final void volume fraction, $f_{\mathrm{f}}$, is reached, where the material looses its stress carrying capacity and where the damage variable achieves ist ultimate value, $f_{u}^{*}$, which equals $1 / q_{1}$. For this state, $K$ can be calculated if the void volume fraction at final fracture is known from experiments.

As void nucleation is not considered for the present materials the parameters which have to be determined reduce to simply $f_{\mathrm{c}}$, and $q_{1}$. In this case, cell model calculations provide an easy method to determine them.

\section{CELL MODEL CALCULATIONS}

Cell model calculations are widely used to simulate and study the behaviour of porous solids, see e,g. Koplik and Needleman [2], Becker et al. [7], Brocks et al. [8]. The continuum is considered to consist of a periodic assemblage of hexagonal cylindrical unit cells which are approximated by spherical cylinders, Figure 2 , which allow for a simple axisymmetric calculation. Every cell of initial length $2 L_{0}$ and radius $R_{0}$ contains a spherical or ellipsoidal cavity of radius $r_{0}$ or principle axes $a_{0}, b_{0}$, respectively. It is subjected to homogeneous radial and axial displacements, $u_{1}, u_{3}$.

The "mesoscopic" principal strains and the effective strain, respectively, are given by

$$
E_{1}=E_{2}=\ln \left(\frac{R}{R_{o}}\right) ; \quad E_{3}=\ln \left(\frac{L}{L_{o}}\right) ; \quad E_{e}=\frac{2}{3}\left|E_{3}-E_{1}\right|
$$

The correspondent "mesoscopic" true principal stresses, $\Sigma_{1}=\Sigma_{2}, \Sigma_{3}$, are the average reaction forces at the cell boundaries over deformed cell face areas. Here and in the following, capital letters, $\Sigma_{\mathrm{ij}}$, $E_{\mathrm{ij}}$, denote quantities on a "mesoscopic" length scale and small letters, $\sigma_{\mathrm{ij}}$, $\varepsilon_{\mathrm{ij}}$, quantities on a "microscopic" scale, respectively. Effective stress, hydrostatic stress and triaxiality result from 


$$
\Sigma_{e}=\left|\Sigma_{3}-\Sigma_{1}\right| \quad ; \quad \Sigma_{h}=\frac{1}{3}\left(\Sigma_{3}+2 \Sigma_{1}\right) ; \mathrm{T}=\frac{\Sigma_{h}}{\Sigma_{e}}
$$

The current void volume fraction, $f$, is defined as the ratio of the total void volume and the cell volume, $V=\pi R^{2} L$. For an elastic-plastic matrix material there is just one structural void in the center of the cell and, hence, $f$ can be computed via the condition of incompressibility for plastic deformations

$$
(1-f) V-\Delta V^{e}=\left(1-f_{0}\right) V_{0},
$$

where $\Delta V^{e}$ is the increase in the volume of the cylindrical cell due to the elastic dilatation arising from the imposed hydrostatic stress which is approximated by [2]

$$
\Delta V^{e}=\left(1-f_{0}\right) V_{0} \frac{3(1-2 v)}{E} \Sigma_{h}
$$

The initial void volume fraction, $f_{0}$, is simply given by

$$
f_{0}=\frac{2 r_{0}^{3}}{3 R_{0}^{2} L_{0}} \text { or } f_{0}=\frac{2 a_{0}^{2} b_{0}}{3 R_{0}^{2} L_{0}}
$$

in the case of a spherical or ellipsoidal void, respectively.

An axisymmetric FE model of 480 isoparametric quadratic 8-node elements and 1530 nodes as shown in Figure 3 was used for the calculations. The structure is subject to a homogeneous elongation, $u_{3}$, in axial direction and the radial displacement is kept homogeneous, too, by constraint conditions.

If triaxiality shall be kept constant during the loading history the ratio of

$$
\frac{\Sigma_{1}}{\Sigma_{3}}=\frac{3 \mathrm{~T}-1}{3 \mathrm{~T}+2}
$$

has to remain constant. This is realized by the Riks algorithm in ABAQUS, which can easily be applied to cell model calculations, as described in detail in [9].
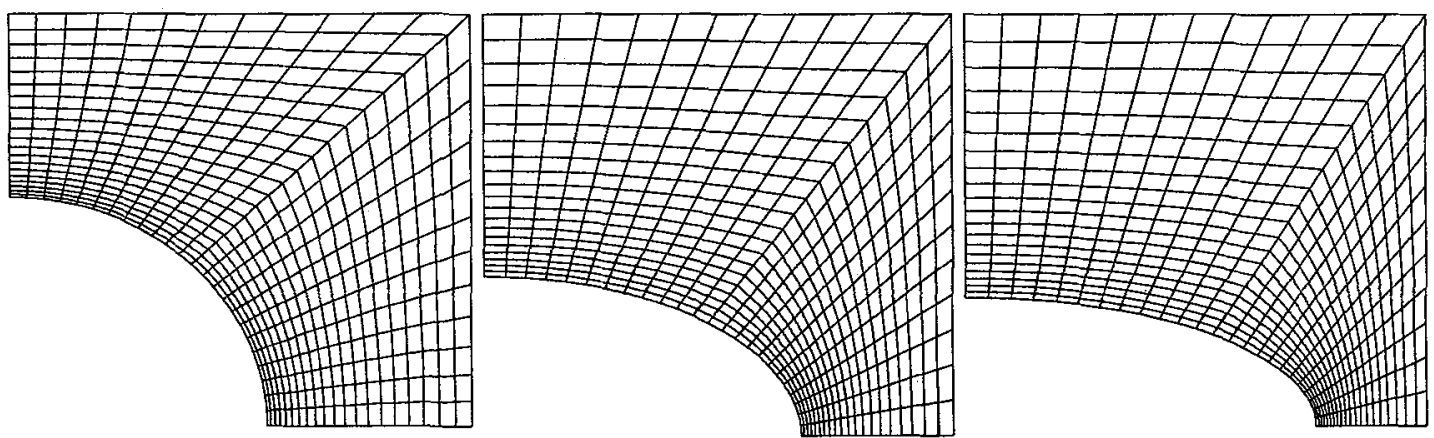

Figure 3: FE-models (one quarter of a cell): $f_{0}=0.114, S_{\mathrm{F}}=1.0(/ 1 \mathrm{AZ})(\mathrm{a}), f_{0}=0.114, S_{\mathrm{F}}=0.7(/ 1 \mathrm{AZ})(\mathrm{b}), f_{0}=0.12$, $S_{\mathrm{F}}=0.7(/ 3 \mathrm{AZ})(\mathrm{c})$

As a reduction of the void diameter occurred in the course of loading for low triaxialities the graphite particle was simulated by a rigid surface in some of the calculations to study the influence of this additional constraint condition on the defomation behaviour of the cell. 
The FE calculations yield the mesoscopic deformation behaviour of the cell from which a mesoscopic effective stress vs strain curve and a void volume fraction vs strain curve can be determined. The critical strain and the critical void volume fraction, $E_{\mathrm{c}}$ and $f_{\mathrm{c}}$, when plastic collapse occurs is obtained as shown in Figure 4a. The mesoscopic radial reduction, $E_{1}$, of the cell remains constant beyond the collapse point whereas the effective strain, $E_{\mathrm{e}}$, and the void volume keep increasing. The values of $f_{\mathrm{c}}$ depend on the triaxiality of the loading, in general, see Figure $4 \mathrm{~b}$ where the solid points denote the calculations with a rigid inclusion.
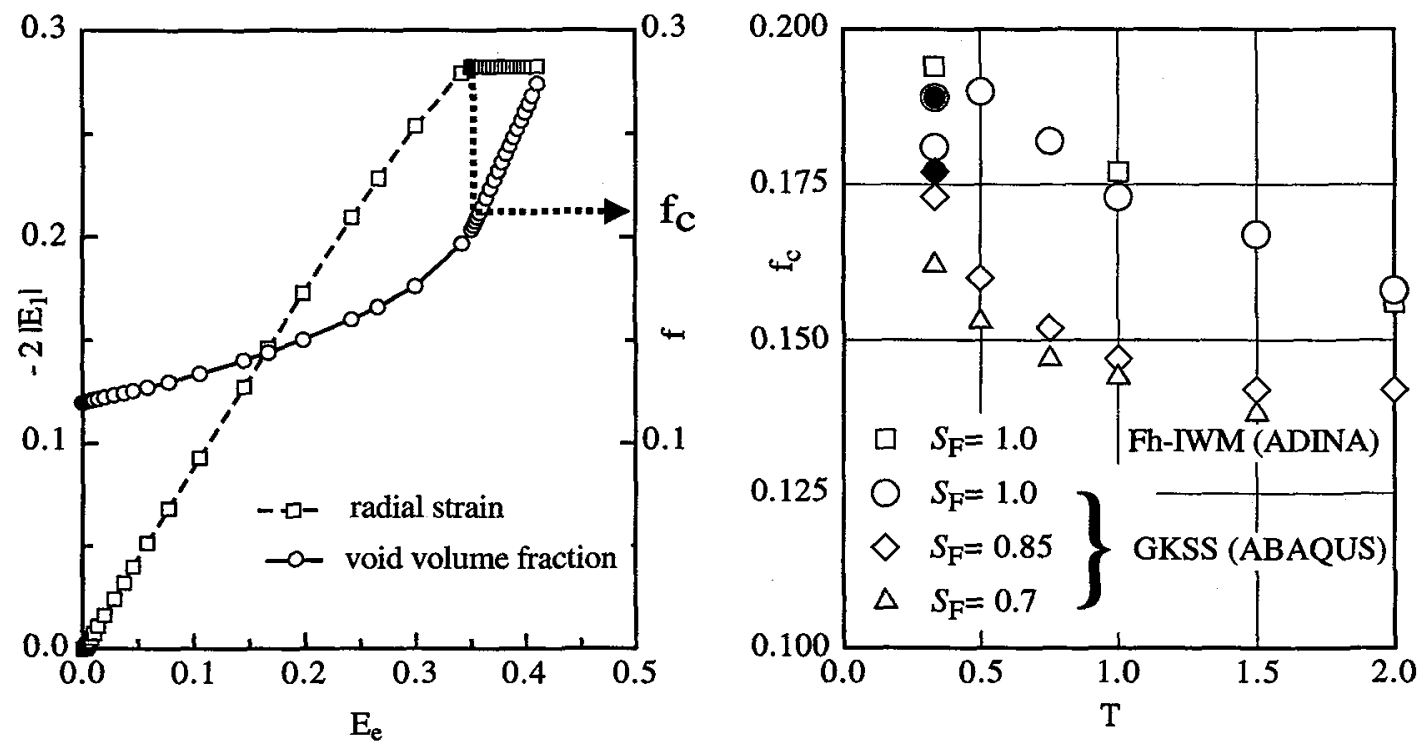

Figure 4: determining plastic collapse of a cell (a), critical void volume fraction as a function of triaxiality (b)

The parameter $q_{1}$ can also be determined from the cell model results at the point of initial plastic yielding of the ferritic bulk material, $\sigma=R_{e L}{ }^{{ }^{e}}$, where the GTN yield function supplies the quadratic equation

$$
q_{1}^{2}-\frac{2}{f_{0}} q_{1} \cosh \left(\frac{3}{2} \mathrm{~T} \frac{\Sigma_{e}}{R_{e L}^{F_{e}}}\right)+\frac{1}{f_{0}^{2}}-\left(\frac{\Sigma_{e}}{f_{0} R_{e L}^{F_{e}}}\right)^{2}=0
$$

It depends much less on the triaxiality. Calculating $q_{1}$ for different triaxialities yields to an average value of $q_{1}=1.5$. The GTN-model as described above assumes that $q_{1}$ and $f_{\mathrm{c}}$, do not depend on the triaxiality. Hence, average values have to be found which fit the various cell model calculations over the whole range of deformation. Figure 5a compares the mesoscopic effective stress vs strain curves of the cell model with spherical inclusion of GGG $40 / 1 \mathrm{AZ}$ for various triaxialities with the uniaxial solutions of the GTNmodel using a "best fit" parameter set, $f_{c}=0.175$ and $q_{1}=1.2$. It was found later by FE simulations of round tensile bars that $q_{1}=1.5$ fits the experimental results much better than $q_{1}=1.2$. In the following, $q_{1}=1.5$ is used. 

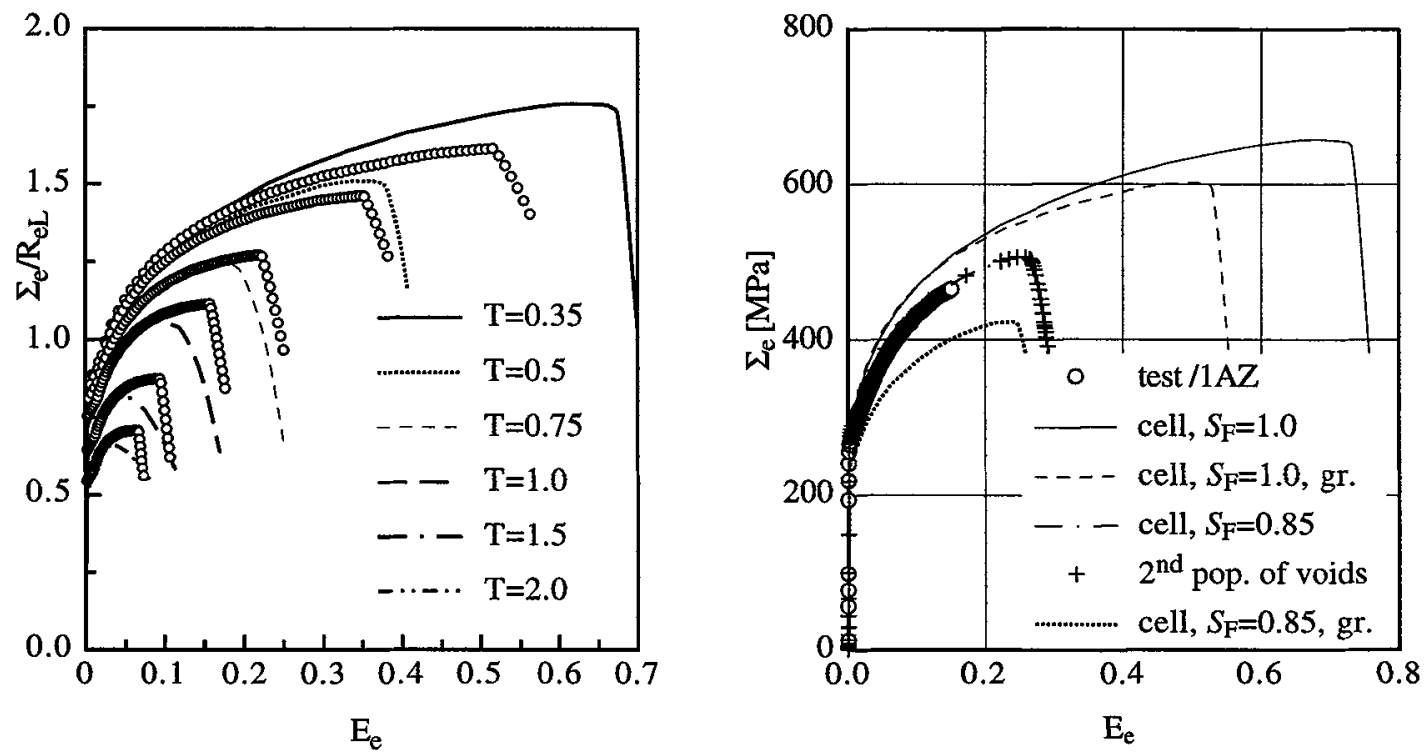

Figure 5: uniaxial solutions of the GTN-model compared to cell model calculations (a), behaviour of a unit cell under uniaxial tension compared to tensile test of GGG-40/1AZ (b)

In Figure $5 b$ the influence of different form factors, $S_{\mathrm{F}}$, and of a rigid inclusion is shown. The critical strain is reduced by both, ellipsoidal cavity and inclusion (gr. in Figure 5 b). For one cell a second population of voids $\left(f_{0}=0.0004\right)$ was assumed, which did not show any effect.

\section{FE SIMULATIONS}

The GTN-model and its parameters obtained from the cell model calculations are now verified by the simulation of "full scale" tests using the ABAQUS program with a special user supplied routine [10]. The first specimen is a standard tensile bar. Due to the high volume fraction of the graphite particles, the initial yield strengths of the GGG and the ferrite matrix material, $R_{p 0.2}{ }^{G G G}$ and $R_{e L}{ }^{F e}$, vary significantly. This gives another possibility of determining $q_{1}$ by the above equation with $T=1 / 3$ and $\Sigma_{\mathrm{e}}=R_{p 0.2}{ }^{G G G}$ from the tensile test data. A $q_{1}$ value of 1.95 is obtained from this. However, the numerical results show that $q_{1}=1.5$ overestimates the experimentally measured forces only slightly and, hence, this value is taken for all the following calculations.

Tvergaard and Needleman [6] referred to the phenomenon that the onset of macroscopic fracture in a tensile test is associated with a sudden drop of the load. Fitting the numerical results to the experimental data at this point has therefore become a common technique to determine $f_{c}$. Varying the value $f_{c}$ showed that elongation, $\Delta L$, and reduction of diameter, $\Delta d$, at fracture could not be met by the calculations at the same time. If $\Delta L$ is met $\Delta d$ is overestimated, if $\Delta d$ is met $\Delta L$ is underestimated. Hence, Poisson's ratio of $\Delta d / \Delta L$ in the tests must differ from the numerical simulations which is displayed in Fig 6. Below maximum load the numerical and experimental data coincide but beyond that point the cross section necking in the simulation is greater than in the experiment. The GTN-model follows approximately the line of the "plastic" Poisson's ratio of 0.5 whereas the test data follow a line of the slope 1/3. Remarkably, the cell model reproduces the experimental effect and follows the test data. This means that the growth of voids as large as in the present material cannot be adequately described by the isotropic plastic potential of the GTN-model and its scalar damage variable if the triaxiality is low. The spherical void does not remain spherical whereas the 
evolution law for the void volume still assumes a self-similar shape. This effect is independent of the inclusions shape, it can be observed at spherical and ellipsoidal inclusions as well. The more dominant this influence is at low triaxialities, the less important it will become at higher triaxialities. This was shown by simulating the load vs elongation behaviour of notched tensile specimen and SE(B)-specimen, where the hydrostatic part of the stress tensor is significantly higher.

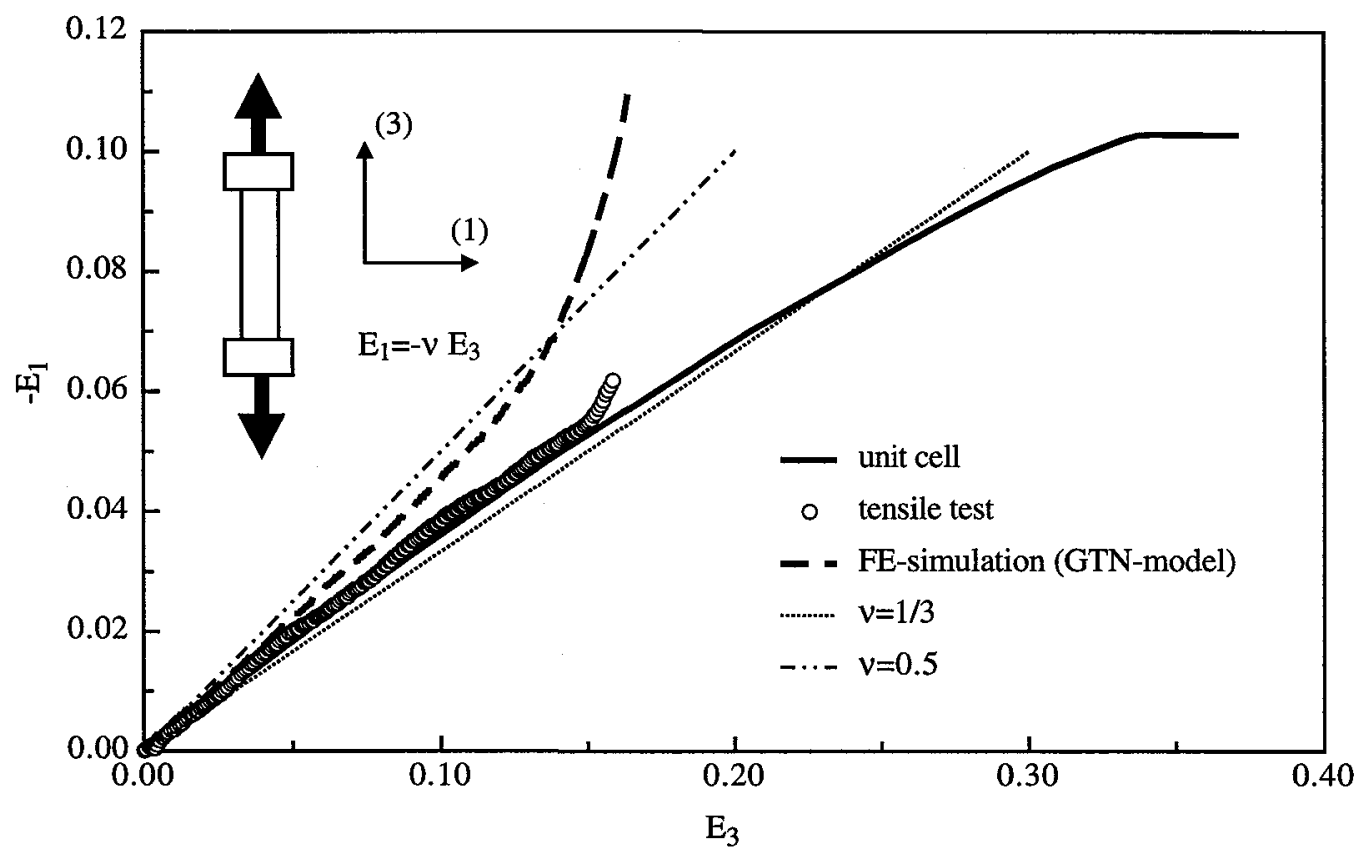

Figure 6: structural behaviour of a tensile bar and a unit cell with ellipsoidal inclusion $\left(S_{\mathrm{F}}=0.85\right)$

While "macroscopic" quantities cause the troubles of matching the fracture point as described above (see Figure 7a), Figure $7 \mathrm{~b}$ shows the variation of damage $f$ along the axis of a round tensile bar which was determined by means of metallographical investigations in comparison to the results of the numerical simulation. A high gradient of damage with a maximum value of $19 \%$ is observed in the region of localized deformation of the broken specimen. The FE simulation also shows a gradient of damage in radial direction in a way that damage decreases from the centre to the surface of the specimen. This means that cracking starts in the centre of the bar which is well-known from experiments.

Finally, the load displacement behaviour and the fracture resistance of a $\mathrm{SE}(\mathrm{B})$ specimen have been simulated. A comparison of experimental and numerical results is displayed in Figure 8. The load is overestimated in the FE calculation due to the assumption of plane strain, see Figure 8a. Figure $8 \mathrm{~b}$ shows the numerically predicted $J_{R}$ curves which coincide quite well with the experimental results. Fracture resistance increases with increasing spacing of graphite inclusions. Of course, the same set of material parameters has been used in the simulations of the fracture mechanics tests as for the tensile tests. While the size of the finite elements at the crack tip for simulation of the material GGG-40/1AZ was $0.3 * 0.4 \mathrm{~mm}^{2}$, it was set to $0.6 * 0.8 \mathrm{~mm}^{2}$ for simulating the specimen made of GGG-40/3AZ. Thus, the element length correlates with the microstructure and is six times the nearest neighbour distance of the inclusions in both cases. 

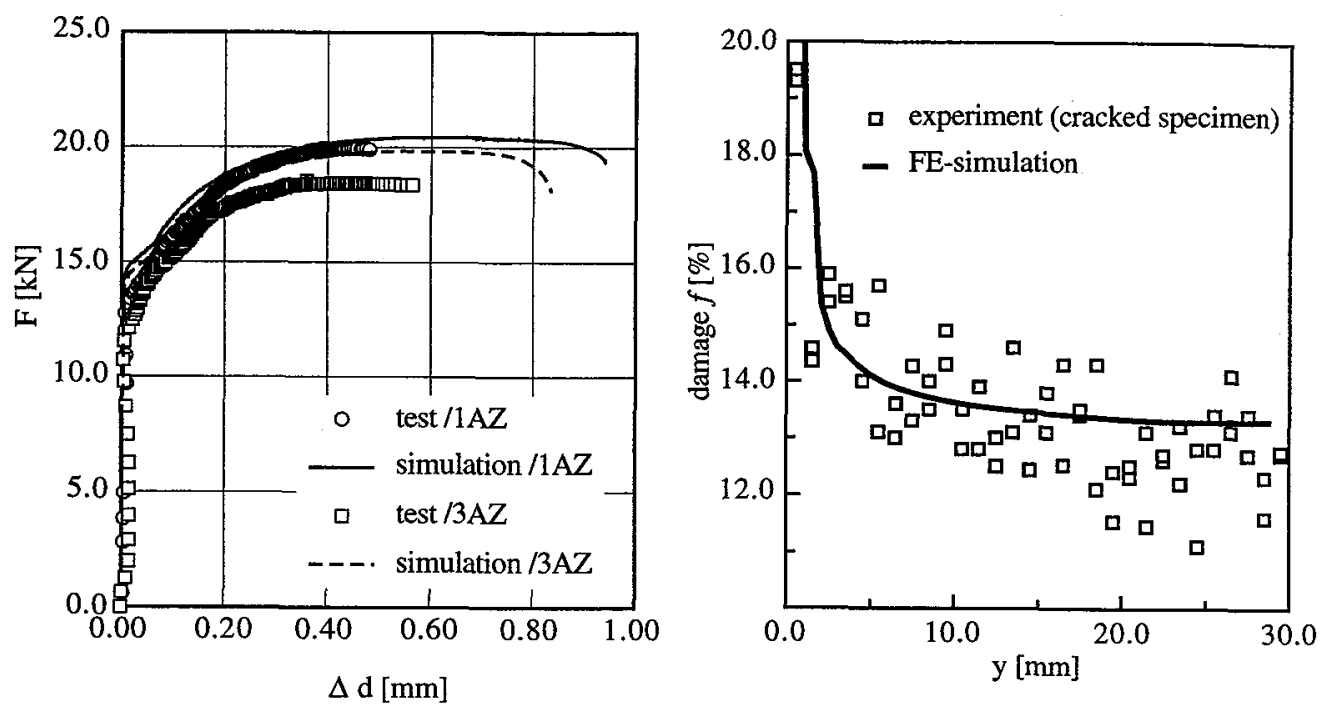

Figure 7: round tensile bar: Force vs reduction of diameter curves of GGG40/1AZ and /3AZ (a), variation of damage along the axis of a round tensile bar (GGG-40/3AZ), (b)
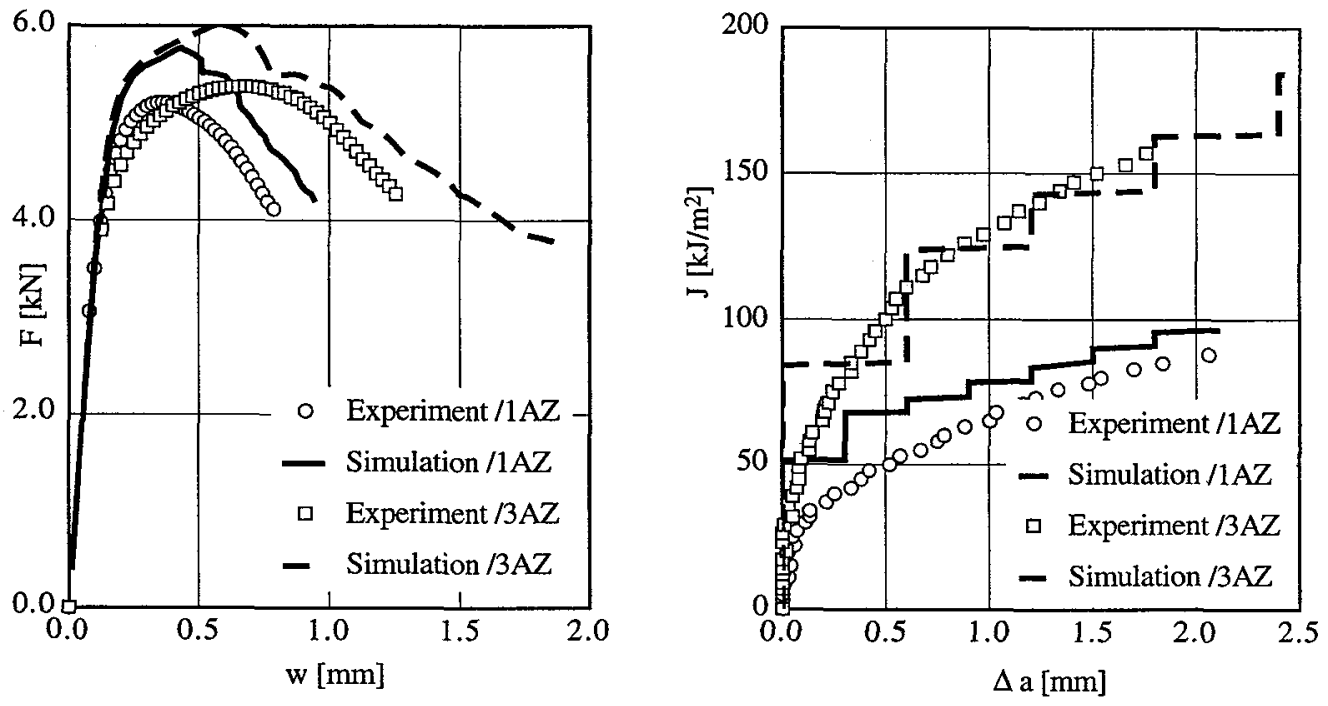

Figure 8: Load displacement curves (a) and fracture resistance curves (b) of a 4-point bend specimen

\section{CONCLUSIONS}

Strength and toughness of two ferritic nodular cast iron materials of the type GGG-40 with different graphite morphology have been characterized by the stress-strain-curve of the ferritic matrix material and particle related parameters like nodule size, spacing and shape. These data allow to identify micromechanical damage parameters used in the GTN-model. 
Whereas the ferritic matrix material and the volume fraction of graphite particles of the two investigated materials is nearly the same they differ by the shape, i. e. spherical or ellipsoidal, size, and distance of the inclusions. The differences in the graphite morphology have little effect on the strength, but a large effect on fracture toughness, as is found experimentally.

To determine the required parameters for the GTN-model FE calculations of a cylindrical cell containing a cavity which represents the void after debonding from the graphite particle have been performed under large strain conditions for different triaxialities. The effect of the graphite particles at low triaxialities was modeled by a rigid surface in the void. It was shown that one gets significant differences at low triaxialities, while at high triaxialities the influence of the graphite can be neglected.

The shape of the inclusion is of major interest for the response of a unit cell. An ellipsoidal reduces the critical void volume fraction, $f_{\mathrm{c}}$, compared with a sphere of the same volume, if the major principal axis is perpendicular to the load axis.

Simulations of tensile tests with smooth and notched specimens provide additional information to verify the micromechanical parameters obtained from metallographic observations and cell modell calculations. It was found, that the ratio of elongation of the specimem and its reduction of diameter differs significantly between experiment and FE simulation. This means that the isotropic plastic potential of the GTNmodel and its scalar damage variable are not able to describe the deformation behaviour adequately for voids as large as in the present material if the triaxiality is low.

$\mathrm{J}_{\mathrm{R}}$ curves can be predicted by FE calculations of SE(B) specimens. The predictions fit the experimental data quite well. The different particle size and distance of the two GGG-materials is taken into account by varying the element size in the ligament. The element length correlates with the microstructure and is six times the nearest neighbour distance of the inclusions in both cases.

\section{Acknowledgements}

This work was financially supported by the Deutsche Forschungsgemeinschaft (DFG). The authors greatfully acknowledge this support.

\section{References}

[1] Mudry, F. and di Fant, M.:"A round robin on the meadurement of local criteria", IRSID Report RI $93.334,1993$

[2] Koplik, J. and Needleman, A.: "Void growth and coalescence in porous plastic solids", Int. J. Sol. Struct. 24, 1988, 835-853

[3] Rice, J. R. and Tracey, D.M.: "On the ductile enlargement of voids in triaxial stress fields", J. Mech. Phys. Solids 17 (1969), 201-217

[4] Gurson, A. L.: "Continuum theorie of ductile rupture by void nucleation and growth: Part I - yield criteria and flow rules for pourous ductile media", J. Eng. Mater. Tech. 99, 1977, 2-15

[5] Tvergaard, V.:" Ductile fracture by cavity nucleation between larger voids", J. Mech. Phys. Solids 30, (1982)

[6] Tvergaard, V.and Needleman, A.:"Analysis of the cup-cone fracture in a round tensile bar", Acta Metall. 32 (1983), 157-169

[7] Becker, R., Smelser, R. E., Richmond, O. and Appleby, E.J.: "The effect of void shape on void growth and ductility in axisymmetric tension tests", Metallurgica Transactions 20 A (1989), pp. 853 861

[8] Brocks, W., Sun, D. Z. and Hönig, A.: "Verification of the transferability of micro-mechanical parameters by cell model calculations with visco-plastic materials", Int. J. Plasticity 11, 1995, 971-998

[9] Eberle, A. and Klingbeil, D.: "Die Durchführung von Zellmodellrechnungen mit dem FE-Programm ABAQUS und der Riks-Methode", BAM-V.31 Bericht 96/1, BAM Berlin, 1996

[10]Hao, S.and Brocks, W.: The Gurson-Tvergaard-Needleman-model for temperature and strain-rate dependent material with isotropic and kinematic hardening, Technical Note GKSS/WMG/95/1, GKSSForschungszentrum, 1995 